\title{
Self-reported healthcare waste segregation practice and its correlate among healthcare workers in hospitals of Southeast Ethiopia
}

Biniyam Sahiledengle (D)

\begin{abstract}
Background: The key to the effective management of healthcare wastes is segregation of the waste at the point of generation; no matter what final strategy for treatment and disposal of wastes is selected, it is critical that waste streams are separated. In Ethiopia, healthcare waste segregation practice among healthcare workers is overlooked and scarcely addressed in the scientific literature. This hospital-based cross-sectional study was, therefore, conducted to assess healthcare waste segregation practice and its correlate among healthcare workers in Bale zone, southeast Ethiopia.

Methods: All five hospitals found in Bale zone were included and the study participants were selected using a systematic sampling technique from each hospital. Data were collected through interview using structured questionnaires. Descriptive statistics were computed. Bivariate and multivariable logistic regression analyses were employed to identify factors that correlate with healthcare waste segregation practice.

Results: A total of four hundred and nine healthcare workers participated in the study, for a response rate of 97.4\%. Of these, 220(53.8\%) (95\% Cl: 49.1-58.9) of healthcare workers were found to have reported good healthcare waste segregation practice. Being male gender ( $A O R=1.70,95 \% \mathrm{Cl}: 1.04-2.78)$, less than 30 years of age $(A O R=2.02,95 \% \mathrm{Cl}: 1.06-3.84$ ), less than 2 years work experience ( $A O R=2.95,95 \% \mathrm{Cl}$ : 1.39-6.26), having good self-reported standard precaution practice (AOR $=8.47,95 \% \mathrm{Cl}: 4.98-14.42$ ), and working in a department with an on-site healthcare waste segregation container ( $A O R=2.10,95 \% \mathrm{Cl}: 1.24-3.55$ ) were factors that correlated with self-reported healthcare waste segregation practice.

Conclusion: Overall, only half of the healthcare workers had good healthcare waste segregation practice, which is low and unsatisfactory. Less service year, having good standard precaution practice, and the presence of onsite waste segregation container were the most important variables that correlate with self-reported healthcare waste segregation practice. Therefore, to improve healthcare waste segregation practice health authorities should focus on sufficient allocation of onsite waste receptacles. In addition, periodic training on standard precaution will improve compliance with segregation practice.
\end{abstract}

Keywords: Healthcare waste, Biomedical wastes, Sharps, Infectious waste, Hospitals, Segregation, Waste management, Ethiopia

(c) The Author(s). 2019 Open Access This article is distributed under the terms of the Creative Commons Attribution 4.0 International License (http://creativecommons.org/licenses/by/4.0/), which permits unrestricted use, distribution, and reproduction in any medium, provided you give appropriate credit to the original author(s) and the source, provide a link to the Creative Commons license, and indicate if changes were made. The Creative Commons Public Domain Dedication waiver (http://creativecommons.org/publicdomain/zero/1.0/) applies to the data made available in this article, unless otherwise stated. 


\section{Background}

In performing healthcare activities, healthcare facilities (HCFs) generate healthcare waste $(\mathrm{HCW})$ that could be potentially harmful to healthcare workers, the public and the environment [1]. Injuries, the transmission of infections, environmental pollution, fire hazards, and public nuisances (offensive smells, unsightly debris, etc.) are the major risks and hazards of poorly managed $\mathrm{HCW}[2,3]$. Hence, management of healthcare wastes requires special attention and needs to be assigned high priority [4-6].

Safe healthcare waste management (HCWM) practices reflect the quality of the services in any $\mathrm{HCF}$, and it includes all activates of waste generation, segregation, transportation, storage, treatment and disposal $[7,8]$. The key to minimization and effective management of $\mathrm{HCW}$ is segregation of the waste at the point of generation; no matter what final strategy for treatment and disposal of wastes is selected, it is critical that waste streams are separated to protect both humans and the environment $[9,10]$.

Segregation means separating different wastes into different color-coded bins with liners or sharps containers at locations where they are generated, and it is always the first and the most important activity in $\operatorname{HCWM}[3,11]$. The absence of proper HCW segregation increases the risk of occupational injury and blood born viral infections, particularly among waste handlers, as a result, waste handlers should never sort through waste after it has been placed in a bin $[3,11]$. To overcome such problem, the Federal Ministry of Health of Ethiopia recommended color coding waste segregation practice in all healthcare facilities. The recommended color coding scheme is a black bin with liner for non-infectious wastes, a yellow bin liner with biohazard symbol for infectious wastes, a red bin liner with biohazard symbol for pathological and anatomical wastes, a brown bin with liner for chemicals wastes, yellow bin with radioactive label for radioactive wastes, and yellow box marked "SHARPS" with biohazard symbol for sharps [3].

The World Health Organization (WHO) estimated, around $75-90 \%$ of the waste produced by hospitals are general or non-hazardous wastes comparable to domestic wastes, while the remaining $10-25 \%$ is regarded as hazardous and may impose risks due to infectious, pathological, chemical and radioactive materials or sharps [9]. In most cases this proportion can be achieved by proper segregation of waste streams; if the infectious component is mixed with the general waste stream, the entire mass becomes potentially infectious [11].

Currently, in many developing countries, poor segregation and the question of how to manage HCWs has become a critical concern $[2,11,12]$. The problem got particular attention back in 2002 by the WHO. The study conducted by WHO in 22 developing countries showed that the proportion of facilities that did not manage waste properly and used inappropriate waste disposal methods ranged between 18 and 64\% [12]. Similarly, other recent studies also reported the quantity of HCWs has risen sharply in recent years accompanied by inadequate HCWM [13-19]. Moreover, studies from Greece and Brazil demonstrate that inappropriate segregation practice leads to an increase in the amount of infectious waste generation $[17,18]$.

In Ethiopia, as in many developing countries, compliance with the recommended HCW segregation practice still not jumped from paper $[4,6,16]$. Moreover, safe HCWM has been given very little attention and many facilities do not meet the minimum standards required for proper handling of HCWs $[7,16]$. The previously conducted studies showed that the proportion of $\mathrm{HCW}$ generation is significantly higher than the WHO threshold; the WHO threshold is $80 \%$ general HCW, $15 \%$ pathological and infectious waste, $1 \%$ sharps waste, $3 \%$ chemical or pharmaceutical waste, and less than $1 \%$ special waste, such as radioactive or cytostatic waste, pressurized containers or broken thermometers and used batteries [19-24]. For example, a study conducted in six hospitals of Addis Ababa (Ethiopia) shows that the proportion of hazardous HCW ranges from 29.5 to $53.12 \%$ [21]. In Menellik II hospital (Ethiopia), the proportion of infectious waste was $53.73 \%$ [25]. In the north and south Ethiopia, the proportions of infectious wastes in hospitals were 34.3 and $53 \%$, respectively $[19,26]$. In general, these figures are about three to four times greater than the threshold value recommended by WHO [9]. The foremost explanation for the different estimates regarding the share of general and hazardous constituents of HCW generation may be due to the possibility that segregation of hospital waste streams is weak [16, 22, 27, 28]. In addition, a lack of enforced public health regulations for HCWs segregation may exacerbate the current situation $[16,27,29]$.

Poor segregation of HCWs can result in additional costs related to $\mathrm{HCW}$ disposal and poses various environmental and public health threats $[18,30]$. However, proper segregation of HCWs should result in a clean solid waste stream which can be easily, safely and cost-effectively managed through recycling, composting and landfilling [10]. The volume of waste in the overall HCWs stream could be reduced by as much as $60 \%$ through careful segregation of items [31]. In this regard, understanding the underlying factors associated with $\mathrm{HCW}$ segregation behaviors is a vital step towards developing interventions to improve the waste management system [32]. Therefore, the aim of this study was to determine HCW segregation practice and to identify factors that correlate with $\mathrm{HCW}$ segregation practice among healthcare workers in hospitals of Bale zone, southeast Ethiopia.

\section{Methods}

\section{Study design and setting}

A hospital-based cross-sectional study was done from March 1 to 28, 2018. The study includes all hospitals found 
in Bale zone (namely Goba referral hospital, Ginnir general hospital, Robe general hospital, Dellomena general hospital and Madda Walabu primary hospital) in southeast Ethiopia. Bale zone is located $445 \mathrm{~km}$ away from Addis Ababa, the capital city of Ethiopia. At the time of this study, there were a total of 758 fulltime healthcare workers working in all hospitals, according to Bale zone human resources 2017 annual report.

\section{Study participants}

The source population of the study includes all healthcare workers found in five Bale zone hospitals. The study populations were all selected healthcare workers in five Bale zone hospitals. All healthcare workers who have the qualification of medical doctors, health officers (health officers are trained with the knowledge and skills that are required to solve and manage the common clinical disorders and the potentially preventable public health problems in primary health care settings, such as district hospital and health center), nurses, midwives, and laboratory technician/technologist who work at least 6 months in the care of patient were included in the study. Healthcare workers who work at least 6 months and above included, since in Ethiopian public healthcare facilities 6 month is the minimum trial period for any healthcare professional before he/she accepted as full employed healthcare workers. Healthcare workers who were on maternal leave during the data collection period were excluded (four healthcare workers were excluded since there are on maternity leave and two healthcare workers were on annual leave).

\section{Sample size determination and sampling procedure}

The sample size was determined using Epi Info ${ }^{\mathrm{Tm}}$ 7.1.1.14 statistical software (Center for Disease Control and Prevention, 2013) using single population proportion formula with the assumption of 95\% confidence level, 5\% precision and considering the proportion of healthcare workers who correctly practiced HCWs segregation was 46.3\% in Gondar university hospital [30], and considering a possible non-response rate of $10 \%$. The calculated sample size was $(n=420)$.

First, the calculated sample size $(n=420)$ was distributed to each Bale zone hospitals proportional to the size of healthcare workers. Thereafter, a systematic sampling technique was employed to select health care workers from the sampling frame (Additional file 1: The schematic presentation of sampling procedure).

\section{Variables and measurement}

The dependent variable of the study was healthcare workers self-reported HCW segregation practice. HCW segregation practice was measured by enquiring whether the respondent had practiced the recommended $\mathrm{HCW}$ segregation practice in their workplace using eight (yes/ no) questions, each correct segregation practices was awarded one point and if not zero. Afterward, the total practice score of the respondent was calculated and summed up to give the overall practice. Then, healthcare workers who had scored six and above value $(\geq 75 \%)$ of the cumulative score on HCWs segregation questions were labeled as "good practice" if not "poor practice". According the Federal Ministry of Health infection prevention and patient safety guideline recommendation for HCWM practice, the minimum HCWs segregation technique in Ethiopia is to segregate HCWs into three compartments (general, infectious and sharp wastes). Following this recommendation, the study considered those three HCWs segregation practice and other interconnected activities, as a result a score of 6 and above value (out of 8 items that $\geq 75 \%$ ) was determined as a cut of point.

The independent variables includes socio-demographic factors (sex, age, marital status, years of service, educational status, and profession), institutional factors (availability of on-site waste collection container, training about HCWM, presence of guideline/standard operating procedure (SOP) or instructive poster on HCW segregation) and individual related variables (standard precaution practice, awareness on the different categories of $\mathrm{HCW}$, awareness on safe management of $\mathrm{HCW}$, and attitude towards $\mathrm{HCW}$ segregation.

To determine healthcare workers standard precautions practice; the respondents were asked ten questions to assess their overall standard precautions practice. Each correct standard precaution practice was awarded one point, otherwise zero. Afterward, a composite score was constructed and healthcare workers standard precaution practice was classified as good (if equal to and above the mean) and poor (below the mean). The mean was considered as a cut of point seeing the result was normally distributed (Additional file 2).

Attitude towards HCW segregation variables comprised of 6 statements with response categories "agree", "disagree" or "neutral". Composite scores were calculated and those scored equal to and above the mean value for the composite score of attitude questions were labeled as having "favorable attitude" towards HCWs segregation, if not "unfavorable attitude" [30].

\section{Data collection and quality}

An interviewer administrated a pre-tested structured questionnaire was used for data collection. The data collection tool was developed by the author considering the national healthcare waste management guideline [33] and related kinds of literature $[3,7,9,34]$ (Additional file 3). The data collection tool was first developed in English and translated to Amharic (local language) then back-translated to English in order to assure consistency of the questions. Pre-testing was done in 21 healthcare workers out of the study area to 
reduce measurement bias. The questionnaire was also tested for internal consistency using Cronbach's alpha test and a score of 0.791 and 0.835 was obtained for healthcare waste segregation and standard precaution practice questionnaires, respectively.

Five trained BSc nurses (who were from another healthcare facility that were not included in the study) collected data through a face-to-face interview. To enhance the quality of data one-day training was given for data collectors and supervisors regarding the aim of the study, data collection procedure, and data collection tool. Before data collection, all participants were fully informed regarding the objective of the study, and informed consent was obtained from each study participant. The collected data were treated as confidential. The completeness and consistency of the questionnaire were checked by two supervisors and by principal investigator throughout the data collection period.

\section{Statistical analysis}

Data analysis was undertaken using SPSS version (20.0). Descriptive statistics such as frequencies, mean and standard deviation were computed. Binary and multivariable logistic regression models were employed to identify factors associated with self-reported $\mathrm{HCW}$ segregation practice. All the independent variables were tested for possible multicollinearity before putting those into the multivariable logistic regression models. And variables with a $p$-value of less than 0.25 in the bivariate analysis were then entered into a multivariable logistic regression to control the effect of confounders [35]. Adjusted Odds ratios (AOR) with corresponding 95\% confidence interval $(\mathrm{CI})$ were estimated to assess the strength of association and for all statistically significant tests $p$-value $<0.05$ was used a cut-off point. The overall goodness of fit was checked using the Hosmer and Lemeshow test.

\section{Results}

\section{Socio-demographic and other characteristics of} healthcare workers

A total of 409 healthcare workers participated in the study for a response rate of $97.4 \%$. Among these participants $210(51.3 \%)$ healthcare workers were males and 199(48.7\%) were females, with a male to female ratio of 1.1: 1. The mean (standard deviation (SD)) age of HCWs were $28.12( \pm 5.18)$, and $176(43.0 \%)$ had more than fiveyear work experience (Table 1 ).

Of the total respondents, only 53(13.0\%) of healthcare workers received training related to HCWM in past 1 year preceding the study period. Regarding healthcare workers knowledge on the different types of healthcare wastes, 322 (78.7\%) of healthcare workers correctly know the different types of HCWs, such as sharps, infectious and general wastes. Two hundred and sixty-six (65.0\%) of the respondent had awareness of HCWs segregation by type.
Table 1 Socio-demographic, individual and health facility related variables of healthcare workers in hospitals of Bale zone, Southeast Ethiopia March $2018(n=409)$

\begin{tabular}{llll}
\hline Variables & Category & Frequency & $\%$ \\
\hline Sex & & & \\
& Male & 210 & 51.3 \\
& Female & 199 & 48.7 \\
Age (years) & & \\
& $<25$ & 80 & 19.5 \\
$25-29$ & 213 & 52.1 \\
& $30-34$ & 83 & 20.3 \\
& 235 & 33 & 8.1
\end{tabular}

Marital status

$\begin{array}{lll}\text { Married } & 221 & 54.0\end{array}$

Single $\quad 188 \quad 46.0$

Years of service (years)

$\begin{array}{lll}<2 \text { years } & 116 & 28.4 \\ 2-5 \text { years } & 117 & 28.6 \\ >5 \text { years } & 176 & 43.0\end{array}$

Hospital type

Referral $\quad 159 \quad 38.9$

General $\quad 218 \quad 53.3$

$\begin{array}{lll}\text { Primary } & 32 & 7.8\end{array}$

Current working department

$\begin{array}{lll}\text { Internal medicine } & 69 & 16.9\end{array}$

$\begin{array}{lll}\text { Surgical ward } & 55 & 13.4\end{array}$

$\begin{array}{lll}\text { Pediatrics ward } & 33 & 8.1\end{array}$

Neonatal intensive care unit (NICU) $\quad 23 \quad 5.6$

Obstetrics and Gynecology $\quad 98 \quad 23.9$

$\begin{array}{lll}\text { Operating room (OR) } & 21 & 5.1\end{array}$

$\begin{array}{lll}\text { Emergency-unit } & 29 & 7.1\end{array}$

Outpatient department (OPD) $\quad 45 \quad 11.1$

$\begin{array}{lll}\text { Laboratory } \text { and others }^{\mathrm{a}} & 36 & 8.8\end{array}$

Profession

Nurses and midwifery $\quad 254 \quad 62.1$

$\begin{array}{lll}\text { Physician and health officer } & 57 & 13.9\end{array}$

Laboratory technicians and technologist $\quad 98 \quad 24.0$

Educational status

First degree and above $\quad 228 \quad 55.7$

Diploma $181 \quad 44.3$

Presence of guideline, SOP or instructive poster on HCW segregation

$\begin{array}{lll}\text { Yes } & 237 & 57.9\end{array}$

$\begin{array}{lll}\text { No } & 172 & 42.1\end{array}$

Ever taking training in HCWM methods

$\begin{array}{lll}\text { Yes } & 53 & 13.0\end{array}$

$\begin{array}{lll}\text { No } & 356 & 87.0\end{array}$ 
Table 1 Socio-demographic, individual and health facility related variables of healthcare workers in hospitals of Bale zone, Southeast Ethiopia March $2018(n=409)$ (Continued)

\begin{tabular}{lll}
\hline Variables Category & Frequency & $\%$ \\
\hline Know the different categories of HCWs & 322 & 78.7 \\
Yes & 87 & 21.3 \\
No & & \\
Awareness on HCW segregation & 266 & 65.0 \\
Yes & 143 & 35.0 \\
No & & \\
Standard precaution practice & 215 & 52.6 \\
Good & 194 & 47.4 \\
Poor & & \\
Attitude towards HCW segregation & 249 & 60.9 \\
Favorable & 160 & 39.1 \\
\hline
\end{tabular}

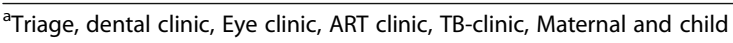
health unit

In addition, standard precautions practice of healthcare workers were assessed for the main components like (proper use of personal protective equipment, hand hygiene practice, safe injection practice, preventing of nosocomial infection, and waste management practice) and 215(52.6\%) [95\%CI: 47.4-57.0] had good standard precautions practice and 249 (60.9\%) [95\%CI: 56.2-65.5] had a positive attitude towards HCW segregation (Table 1).

\section{Self-reported healthcare waste segregation practice}

Two hundred and twenty (53.8\%) [95\% CI: 49.1-58.9] healthcare workers had self-reported good HCWs segregation practice. And 139 (33.9\%) of healthcare workers only segregate $\mathrm{HCW}$ for their last client.

\section{Observational results on $\mathrm{HCW}$ treatment and disposal practice}

Table 2 shows the result of the observational assessment. From the empirical observation; all hospital treated and disposed of there HCW on-site. And all hospital practiced open pit burning of HCW. Even though, all hospitals have brick incinerator it was witnessed that all incinerator have some form of problem in terms of designing and construction. With respect to the disposal of the treated HCWs, all hospitals used open damping of HCWs in their compound (Figs. 1, 2, 3, 4 and 5).

\section{Factors associated with healthcare waste segregation practice}

In the bivariate analysis factors which were significantly associated with good self-reported HCWs segregation practice were: age, year of service, hospital type, current working department, profession, ever taking training in HCWM methods, awareness on HCW segregation, awareness on the different categories of $\mathrm{HCWs}$, standard precaution practice and presence of on-site HCW segregation containers. After controlling the confounding in multivariable logistic regression analysis; gender, age, year of service, profession, standard precaution practice and presence of on-site $\mathrm{HCW}$ segregation containers were found to be significantly associated with good self-reported HCWs segregation practice.

To check the correctness of the final model, the Hosmer and Lemeshow test for the overall goodness of fit was used, and a value of 0.381 was obtained; that is not significant, which means the final model was correct. The result of the final model showed that male healthcare workers were 1.7 times more likely to had good self-reported HCW segregation practices than female healthcare workers (AOR $=1.70$, 95\% CI: 1.04-2.78). Those healthcare workers who are less than 30 years old were about 2 times more likely to had good self-reported HCW segregation practice than those who are 30 years or older (AOR $=2.02$, 95\% CI: 1.06-3.84). The study further identified those healthcare workers who served less than 2 years were about three times more likely to had good self-reported HCW segregation practice than those healthcare workers with greater than 5 years work experience (AOR $=2.95$, 95\% CI: 1.39-6.26).

In this study, physicians and health officers were $55 \%$ times less likely to had good self-reported HCW segregation practice than nurses and midwives $(\mathrm{AOR}=0.45,95 \%$ CI:0.21-0.98). Additionally, laboratory technicians/technologists were about 2.8 times more likely to had good self-reported HCW segregation practice than nurses and midwives $(\mathrm{AOR}=2.80,95 \% \mathrm{CI}: 1.49-5.26)$. The study also revealed that healthcare workers who had good self-reported standard precaution practices were about eight times more likely to had good self-reported HCW segregation practice than their counterpart $(\mathrm{AOR}=8.47,95 \% \mathrm{CI}$ : 4.98-14.42). Furthermore, those healthcare workers who were working in the department having on-site $\mathrm{HCW}$ segregation containers were about 2.1 times more likely to had good self-reported HCW segregation practice than their counterpart $(\mathrm{AOR}=2.10,95 \% \mathrm{CI}: 1.24-3.55)$ (Table 3).

\section{Discussion}

Healthcare waste that generated in the course of healthcare activities poses a significant health problem and must be managed accordingly, and the key to the effective management of HCWs is segregation of the wastes at the point of generation [10]. This study aimed to determine HCW segregation practice and its correlate among healthcare workers. The finding from this study suggest that $53.8 \%$ of the healthcare workers had good HCW segregation practice; put general, infectious, and sharp wastes into a different waste collection container. Factors such as gender of 
Table 2 Observational assessment of healthcare waste treatment and disposal practices in Bale zone hospitals, Southeast Ethiopia 2018

\begin{tabular}{ll}
\hline Healthcare waste treatment and disposal practice description $(n=5)^{\mathrm{a}}$ & Yes \\
\hline A designated area for waste treatment and disposal & 5 \\
Waste disposal site fenced & 1 \\
Having walkway to waste disposal site & 3 \\
On-site treatment of HCW practiced & 5 \\
On-site disposal of HCW & 5 \\
Presence of incinerators & 5 \\
Incinerators with some form of problems related to design and construction witnessed & 5 \\
Incinerators had remnants of incompletely burned HCW witnessed at the time of observational assessment & 3 \\
Presence of safe burial & 0 \\
Open pit/ open air/ burning and damping of HCW & 5 \\
Presence of placental disposal pit & 5 \\
Properly constructed watertight ash/needle pit witnessed & 0 \\
Offsite disposal (outsourcing) of HCW & 0
\end{tabular}

${ }^{a}$ Number of hospitals

healthcare worker, age, service year, standard precaution practice, and presence of site waste segregation container were the most important variables that correlate with selfreported healthcare waste segregation practice.

Findings from this study show that a significant number of healthcare workers had poor HCW segregation practice. This finding is similar to studies conducted elsewhere in Ethiopia. For example, a study from Gondar town (north Ethiopia) reported HCW segregation practices was 31.9 and $46.3 \%$ [28, 30]. In addition, different related studies reported HCWM practices in Ethiopia remains a great challenge due to poor $\mathrm{HCW}$ segregation practice $[4,5,24,29,36]$. The present and the previously conducted studies suggested that HCW segregation practice requires special attention, and if the segregation

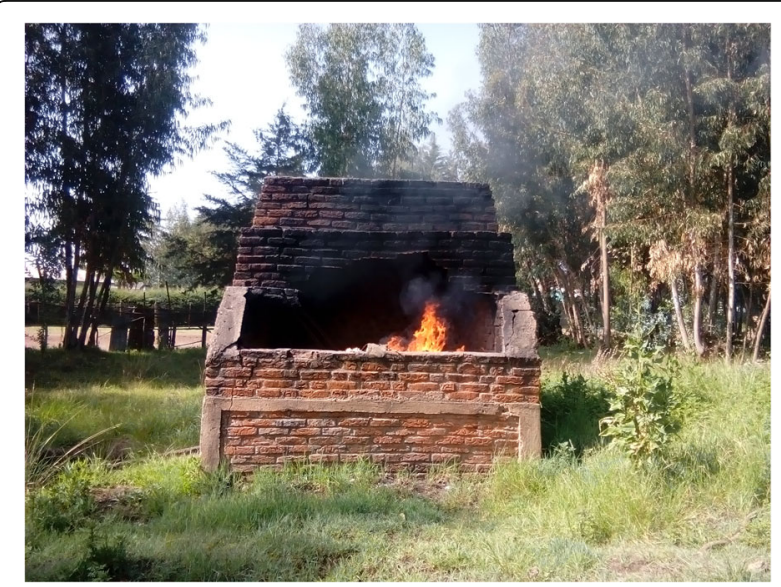

Fig. 1 Poor condition of a brick incinerator at Bale zone hospitals, Southeast Ethiopia, 2018 process is poor or even a very small amount of hazardous waste is added to the general waste category, then the entire mass of the general waste can be unnecessarily polluted by the hazardous waste [16]. In line with this, several studies conducted in Uganda [32], Sudan [37], Iran [38], Jordan [39], Nigeria [40], and China [41] reported poor $\mathrm{HCW}$ segregation practice among healthcare workers.

In the Ethiopian context, multiple factors contribute to poor HCW segregation practice. The first reason may be due to the lack of separate regulation specific for the HCFs to enforce them for the proper management of the hazardous waste. In addition, a systematic review identified that lack of training, lack of awareness, staff resistance, managerial poor commitment, lack of adequate

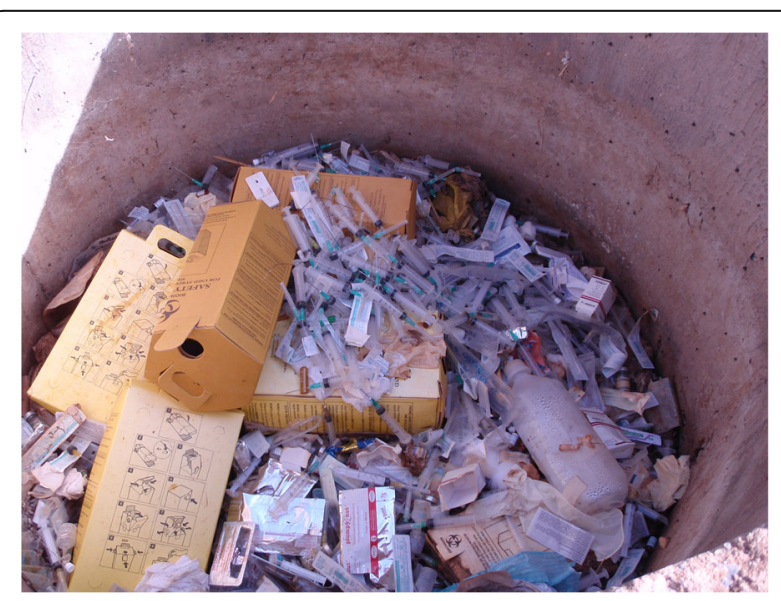

Fig. 2 Indiscriminate disposal of sharp wastes at Bale zone hospitals, Southeast Ethiopia, 2018 


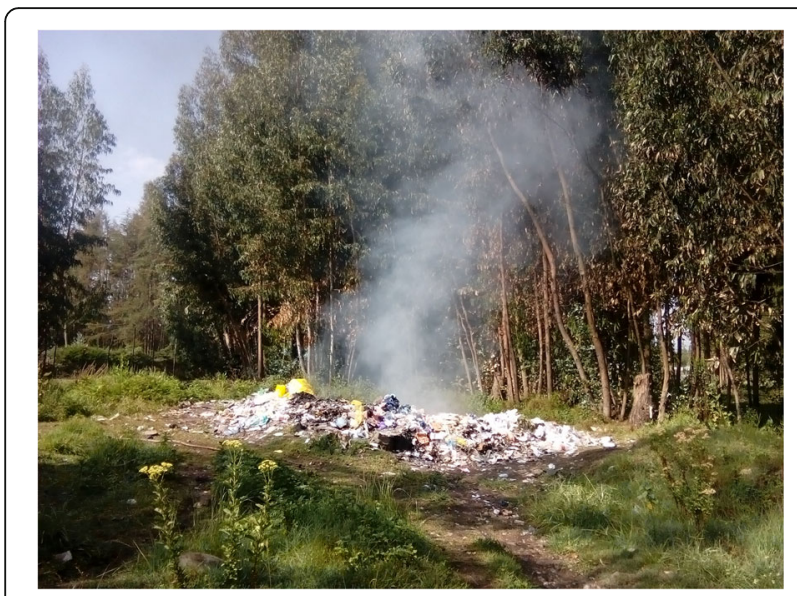

Fig. 3 Open air burning of healthcare wastes at Bale zone hospitals, Southeast Ethiopia, 2018

resources, negligence, and unfavorable attitude towards HCWM were the commonly identified challenges associated with poor HCWM in Ethiopia [16]. A study from Kenya also identified that poor compliance towards HCWM policy is one of the key reason for poor HCW segregation practice [42].

Interestingly, Hagen et al. [43] found that providing instructive posters as a tool to promote effective segregation of HCW appear to be a positive effect on HCW segregation practice among healthcare workers. However, in this study, the presence of instructive poster on $\mathrm{HCW}$ segregation practice was not found to be statistically significant. But, the crude odds ratio suggests that the presence of instructive tools may be associated with an increased odds of good HCW segregation practice. A study from Brazil also reported a similar finding [44].

In this study, healthcare workers who work in the department having on-site $\mathrm{HCW}$ segregation containers

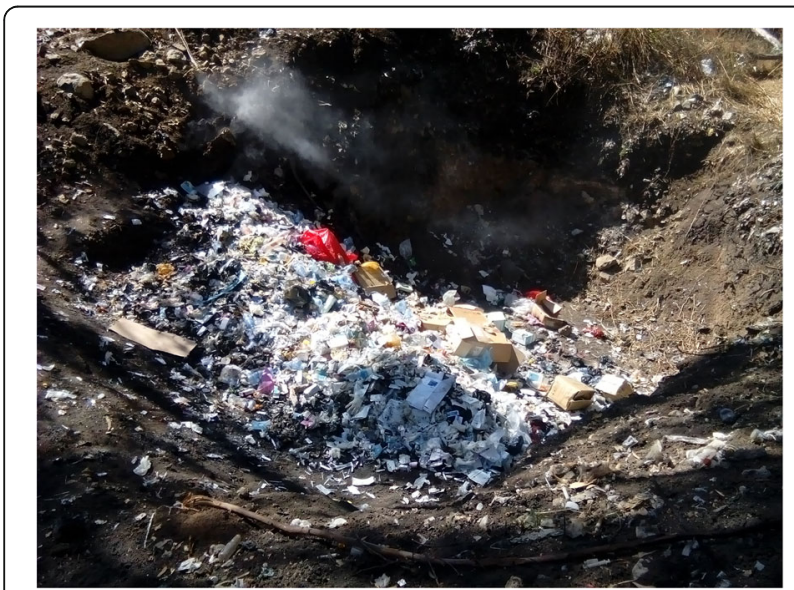

Fig. 4 Open damping of healthcare wastes at Bale zone hospitals, Southeast Ethiopia, 2018

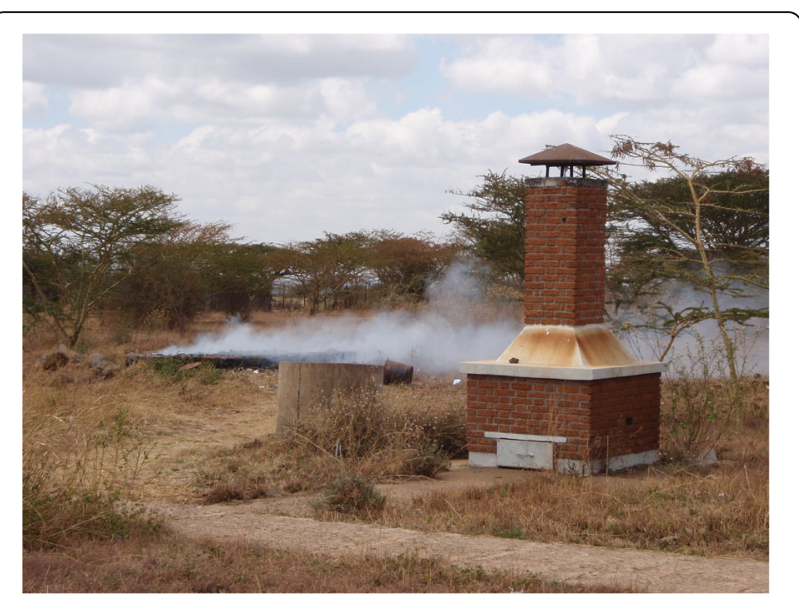

Fig. 5 Uncontrolled and open air burning of healthcare wastes at Bale zone hospitals, Southeast Ethiopia, 2018

were more likely to have good HCW segregation practiced. This finding was in line with a study conducted in Gondar University (Ethiopia) [30]. The finding suggested that the possibility of getting on-site $\mathrm{HCW}$ segregation containers at waste generation point seems to be a positive factor that motivates healthcare workers to segregate HCW. In support of this assertion, studies showed the positive correlation between good HCW segregation practice and presence of on-site color-coded waste collection container [27, 30, 32].

In the present study, almost two-thirds (65\%) of the respondent had awareness of HCW segregation. This finding is lower than a study report from Uganda, 71.8\% [32], and Portugal [45]. This can be attributed to differences in study participants, setting and compliance toward HCWM recommendations.

On the other hand, it was found that the odds of good $\mathrm{HCW}$ segregation practice were 1.7 times more likely among male healthcare workers than female healthcare workers. The possible explanation for this finding might be linked with the standard precaution practice and attitude of male healthcare workers. In this study, the majority of male healthcare workers had good self-reported standard precaution practice and positive attitude towards HCW segregation than female's healthcare which may increase male $\mathrm{HCW}$ segregation practices.

Age of healthcare worker was another socio-demographic factor that significantly associated with self-reported HCW segregation practice. Those young age study participants were about two time's higher odds of good self-reported $\mathrm{HCW}$ segregation practice. Although the reason why younger healthcare workers were more likely to had good HCW segregation practice than their counterparts is beyond the scope of this study, the probable reason is that, in this study younger healthcare workers tend to have less work experience, which is associated with higher odds of self-reported 
Table 3 Factors associated with self-reported HCW segregation practice among healthcare workers in Bale zone hospitals, Southeast Ethiopia 2018

\begin{tabular}{|c|c|c|c|c|}
\hline \multirow[t]{2}{*}{ Variables } & \multicolumn{2}{|c|}{ HCW segregation practice } & \multirow{2}{*}{$\begin{array}{l}\text { Crude } \\
\text { OR (95\% Cl) }\end{array}$} & \multirow{2}{*}{$\begin{array}{l}\text { Adjusted } \\
\text { OR }(95 \% \mathrm{Cl})\end{array}$} \\
\hline & Good $(n=220)$ & Poor $(n=189)$ & & \\
\hline \multicolumn{5}{|l|}{ Sex } \\
\hline Male & 122 & 88 & $1.43(0.97-2.11)$ & $1.70(1.04-2.78)^{* *}$ \\
\hline Female & 98 & 101 & 1 & 1 \\
\hline \multicolumn{5}{|l|}{ Age } \\
\hline$<30$ & 170 & 123 & $1.82(1.18-2.81)^{*}$ & $2.02(1.06-3.84)^{* *}$ \\
\hline$\geq 30$ & 50 & 66 & 1 & 1 \\
\hline \multicolumn{5}{|l|}{ Year of service } \\
\hline$<2$ years & 67 & 49 & $1.53(0.95-2.46)$ & $2.95(1.39-6.26)^{* *}$ \\
\hline $2-5$ years & 70 & 47 & $1.67(1.03-2.68)^{*}$ & $1.76(0.91-3.43)$ \\
\hline$>5$ years & 83 & 93 & 1 & 1 \\
\hline \multicolumn{5}{|l|}{ Hospital type } \\
\hline Referral & 74 & 85 & 1 & \\
\hline General & 124 & 94 & $1.51(1.01-2.29)^{*}$ & \\
\hline Primary & 22 & 10 & $2.53(1.12-5.68)^{*}$ & \\
\hline \multicolumn{5}{|l|}{ Current working department } \\
\hline Internal medicine and surgical & 62 & 62 & 1 & \\
\hline Pediatrics ward and NICU & 25 & 31 & $0.81(0.43-1.52)$ & \\
\hline Obstetrics and Gynecology & 58 & 61 & $0.95(0.58-1.57)$ & \\
\hline The emergency unit, OPD, Laboratory, and others* & 75 & 35 & $2.14(1.26-3.65)^{*}$ & \\
\hline \multicolumn{5}{|l|}{ Profession } \\
\hline Nurses and midwives & 135 & 119 & 1 & 1 \\
\hline Physicians and health officers & 22 & 35 & $0.55(0.31-0.99)^{*}$ & $0.45(0.21-0.98)^{* *}$ \\
\hline Laboratory technicians and technologist & 63 & 35 & $1.59(0.98-2.56)$ & $2.80(1.49-5.26)^{* *}$ \\
\hline \multicolumn{5}{|l|}{ Educational status } \\
\hline First degree and above & 128 & 100 & 1 & \\
\hline Diploma & 92 & 89 & $0.81(0.55-1.19)$ & \\
\hline \multicolumn{5}{|c|}{ Presence of guideline, SOP or instructive poster on HCW segregation } \\
\hline Yes & 129 & 108 & $1.29(0.86-1.94)$ & \\
\hline No & 91 & 81 & 1 & \\
\hline \multicolumn{5}{|l|}{ Ever taking training in HCWM methods } \\
\hline Yes & 37 & 16 & $2.19(1.17-4.07)^{*}$ & $1.96(0.95-4.05)$ \\
\hline No & 183 & 173 & 1 & 1 \\
\hline \multicolumn{5}{|l|}{ Awareness on HCW segregation } \\
\hline Yes & 155 & 111 & $1.68(1.11-2.52)^{*}$ & \\
\hline No & 65 & 78 & 1 & \\
\hline \multicolumn{5}{|l|}{ Awareness of the different categories of HCW } \\
\hline Yes & 162 & 160 & $1.97(1.20-3.25)^{*}$ & \\
\hline No & 58 & 29 & 1 & \\
\hline \multicolumn{5}{|l|}{ Standard precaution practice } \\
\hline Good & 155 & 60 & $5.13(3.36-7.82)^{*}$ & $8.47(4.98-14.42)^{* *}$ \\
\hline Poor & 65 & 129 & 1 & 1 \\
\hline
\end{tabular}

Presence of on-site HCW segregation containers 
Table 3 Factors associated with self-reported HCW segregation practice among healthcare workers in Bale zone hospitals, Southeast Ethiopia 2018 (Continued)

\begin{tabular}{lllll}
\hline Variables & HCW segregation practice & $\begin{array}{l}\text { Crude } \\
\text { OR }(95 \% \mathrm{Cl})\end{array}$ & $\begin{array}{c}\text { Adjusted } \\
\text { OR }(95 \% \mathrm{Cl})\end{array}$ \\
\cline { 2 - 5 } & Good $(n=220)$ & Poor $(n=189)$ & $1.71(1.34-2.58)^{*}$ & $2.10(1.24-3.55)^{* *}$ \\
\hline Yes & 156 & 78 & 1 & 1 \\
No & 64 & & \\
Attitude towards waste segregation & & 112 & $1.14(0.76-1.69)$ \\
Favorable & 137 & 77 & 1 & \\
Unfavorable & 83 &
\end{tabular}

HCW segregation practice as evidence from multivariable logistic regression analysis. In line with this study, a study by Mesfin et al. also reported similar finding [30].

In this study, physicians and health officers were 55\% less likely to have good self-reported HCW segregation practice than nurses and midwives. On the contrary, one study from Gondar (north Ethiopia) indicates that nurses were $73 \%$ less likely to have correct HCW segregation practice than physicians [30]. The possible reason for this inconsistency could be a difference in measurement of the construct items and study facilities; in the previous study, a single hospital was included as opposed to this study which includes five hospitals. In addition, laboratory technicians and technologist were 2.8 times more likely to have good self-reported HCW segregation practice than nurses and midwives. In addition, healthcare workers who had good self-reported standard precaution practice were eight times more likely to have good self-reported HCW segregation practice than their counterparts.

This study had several limitations that need to be considered when interpreting the results. First, the estimated compliance of HCWs segregation practice and their associated factors may be subject to reporting errors, because all the information came from the self-reports of the survey participants. Second, social desirability bias may have been present in the form of the over-reporting of HCW segregation compliance in the survey. Third, the cross-sectional design of the survey did not allow any conclusion in terms of a specific causal direction. Fourth, the reader needs to take precautionary measure while interpreting the study finding since general hospital seems to provide most of the data. One additional limitation of the study is that the data collection tool used in the present study is not validated. Lack of validated questionnaires with acceptable reliability and validity for assessing healthcare waste segregation practice in Ethiopia was the major limitation of the study that limits the present findings. To overcome this problem the study included items that are acceptable face-validly and reliability.

\section{Conclusion}

Overall, only half of the healthcare workers had good healthcare waste segregation practice, which is low and unsatisfactory. Less service year, having good standard precaution practice, and the presence of onsite waste segregation container were the most important variables that correlate with self-reported healthcare waste segregation practice. In order to improve HCW segregation practice, health authorities should consider those identified factors. In addition, continuous mentorship and supervision on HCWM were recommended at all level to safeguard healthcare workers, patients and community from impending consequences as a result of inadequate segregation and indiscriminate disposal of sharp HCW. Moreover, health authorities should focus on sufficient allocation of onsite waste receptacles and on periodic training towards standard precaution will improve compliance with segregation practice. Further study also needed to determine the healthcare workers actual segregation practice.

\section{Additional files}

Additional file 1: The schematic presentation of sampling procedure (PDF 301 kb)

Additional file 2: Standard precaution practice score (PDF $184 \mathrm{~kb}$ ) Additional file $\mathbf{3}$ Data collection tool (PDF 409 kb)

\section{Abbreviations}

AOR: Adjusted odds ratio; Cl: Confidence interval; COR: Crude Odds ratio; HBV: Hepatitis B virus; HCFs: Healthcare facilities; HCV: Hepatitis C virus; HCW: Healthcare wastes; HCWM: Healthcare waste management; HIV: Human Immunodeficiency virus; SOP: Standard Operating Procedure; SPSS: Statistical Package for Social Sciences; WHO: World Health Organization

\section{Acknowledgments}

The author would like to thank Madda Walabu University research and technology transfer director office for providing support letter to conduct the present study and Bale zone health department for their unreserved support. In addition, I would also like to extend my deep appreciation to all the study participants, data collectors and medical directors of the five hospitals. I would like to thank Dr. David Allison for his editorial support while preparing this manuscript. Finally, I would like to acknowledge Mrs. Rahel Niguse (my respected wife) and my Benhanan Biniyam (my son) for their support at a time of manuscript preparation. 


\section{Authors' contributions}

BS conceptualization and investigation, study design, overall supervision, performed the analysis, wrote and approved the final manuscript.

\section{Funding}

No funding was obtained for this research and the cost of this research was completely covered by the author.

\section{Availability of data and materials}

Data will be available upon request from the corresponding authors.

\section{Ethics approval and consent to participate}

Ethical clearance and approval was obtained from Madda Walabu University Ethical Review Committee under reference number PRD/0295/2010. The necessary support letter was obtained from Madda Walabu University research and technology transfer directorate. Permission was secured from all hospital medical directors. All study participants were adequately informed about the objective of the study and communicated that they have the right not to participate in the study or stop the interview at any time they want. In addition, written consent was obtained from all participant healthcare workers prior to an interview. All information obtained in the study was stored confidential and secured.

\section{Consent for publication}

Not applicable.

\section{Competing interests}

The author declares that he has no competing interests.

Received: 12 April 2019 Accepted: 19 August 2019

Published online: 22 August 2019

\section{References}

1. Omar D, Nazli SN, Subramaniam A, Karuppannan L. Clinical waste management in district hospitals of Tumpat, Batu Pahat and Taiping. Procedia Soc Behav Sci. 2012:68:134-45.

2. Kuroiwa C, Suzuki A, Yamaji Y, Miyoshi M. Hidden reality on the introduction of auto-disable syringes in developing countries. Southeast Asian J Trop Public Health. 2004;35:10-1023.

3. Federal Ministry of Health. Infection Prevention and Patient SafetyReference manual for service providers and managers in healthcare facilities of Ethiopia. Addis Ababa: Federal Ministry of Health (FMoH); 2012.

4. Deress T, Hassen F, Adane K, Tsegaye A. Assessment of knowledge, attitude, and practice about biomedical waste management and associated factors among the healthcare professionals at Debre Markos Town healthcare facilities, Northwest Ethiopia. J Environ Public Health. 2018;2018:7672981 10 pages.

5. Doylo T, Alemayehu T, Baraki N. Knowledge and practice of health workers about healthcare waste Management in Public Health Facilities in eastern Ethiopia. J Community Health. 2019;44(2):284-91.

6. Derso S, Taye G, Getachew T, Defar A, Teklie H, Amenu K, et al. Biomedical waste disposal systems of health facilities in Ethiopia. Environ Health Eng Manag J. 2018:5:29-37.

7. Federal Democratic Republic of Ethiopia Ministry of Health. The National healthcare waste management strategy and implementation plan 20122015. Ethiopia: Federal Ministry of Health (FMoH); 2012.

8. Johannessen L, Dijkman M, Bartone C, Hanrahan D, Boyer MG, Chandra C. Healthcare waste management guidance note. Health Population and Nutrition Team: World Bank; 2000

9. Chartier $Y$, editor. Safe management of wastes from health-care activities. Geneva: World Health Organization; 2014.

10. Shaner H, McRae G. Eleven recommendations for improving medical waste management. Burlington: The Nightingale Institute for Health and the Environment; 2006.

11. Gitonga LK. Factors influencing waste segregation among staff in Chuka level four hospital. Rehabil Sci. 2017;2(4):91.

12. Water S, World Health Organization. Safe health-care waste management: policy paper/World Health Organization. 2004.

13. El-Salam MM. Hospital waste management in El-Beheira Governorate, Egypt. J Environ Manag. 2010;91(3):618-29.
14. Tufail $\mathrm{M}$, Khalid $\mathrm{S}$. Heavy metal pollution from medical waste incineration at Islamabad and Rawalpindi, Pakistan. Microchem J. 2008;90(1):77-81.

15. Qaiser S. Survey of sharp waste disposal system in clinics of new Karachi. J Pak Med Assoc. 2012;62(2):163.

16. Yazie TD, Tebeje MG, Chufa KA. Healthcare waste management current status and potential challenges in Ethiopia: a systematic review. BMC Res Notes. 2019;12(1):285.

17. Tsakona M, Anagnostopoulou E, Gidarakos E. Hospital waste management and toxicity evaluation: a case study. Waste Manag. 2007;27(7):912-20.

18. Da Silva CE, Hoppe AE, Ravanello MM, Mello N. Medical wastes management in the south of Brazil. Waste Manag. 2005;25(6):600-5.

19. Tesfahun E, Kumie A, Legesse W, Kloos H, Beyene A. Assessment of composition and generation rate of healthcare wastes in selected public and private hospitals of Ethiopia. Waste Manag Res. 2014;32(3):215-20.

20. Azage M, Kumie A. Healthcare waste generation and its management system: the case of health centers in West Gojjam Zone, Amhara Region, Ethiopia. Ethiop J Health Dev. 2010;24(2):120-26.

21. Debere MK, Gelaye KA, Alamdo AG, Trifa ZM. Assessment of the health care waste generation rates and its management system in hospitals of Addis Ababa, Ethiopia, 2011. BMC Public Health. 2013;13(1):28.

22. Tadesse ML, Kumie A. Healthcare waste generation and management practice in government health centers of Addis Ababa, Ethiopia. BMC Public Health. 2014;14(1):1221.

23. Hayleeyesus SF, Cherinete W. Healthcare waste generation, and Management in Public Healthcare Facilities in Adama, Ethiopia. J Health Pollut. 2016;6(10):64-73.

24. Meleko A, Tesfaye T, Henok A. Assessment of healthcare waste generation rate and its management system in health centers of bench Maji zone. Ethiop J Health Sci. 2018;28(2):125-34.

25. Debalkie D, Kumie A. Healthcare waste management: the current issue in Menellik II referral hospital, ethiopia. Curr World Environ. 2017;12(1): 42-52.

26. Abebe S, Raju RP, Berhanu G. Health care solid waste generation and its management in Hawassa Referral Hospital of Hawassa University, Southern, Ethiopia. Int J Innov Res Dev. 2017;6(5):126-32.

27. Yenesew MA, Moges HG, Woldeyohannes SM. A cross sectional study on factors associated with risk perception of healthcare workers toward healthcare waste management in health care facilities of Gondar town, Northwest Ethiopia. Int J Infect Control. 2012;8(3):1-9.

28. Muluken A, Haimanot G, Mesafint M. Healthcare waste management practices among healthcare workers in healthcare facilities of Gondar town, Northwest Ethiopia; 2014.

29. Haylamicheal ID, Desalegne SA. A review of legal framework applicable for the management of healthcare waste and current management practices in Ethiopia. Waste Manag Res. 2012;30(6):607-18.

30. Mesfin A, Worku W, Gizaw Z. Assessment of health care waste segregation practice and associated factors of health care workers in Gondar University hospital, north West Ethiopia, 2013. Univ J Public Health. 2014;2(7):201-7.

31. Tudor TL, Barr SW, Gilg AW. Strategies for improving recycling behaviour within the Cornwall National Health Service (NHS) in the UK. Waste Manag Res. 2007;25(6):510-6.

32. Akulume M, Kiwanuka SN. Health care waste segregation behavior among health workers in Uganda: an application of the theory of planned behavior J Environ Public Health. 2016:2016:8132306.

33. Federal Ministry of Health of Ethiopia. Healthcare waste management national guideline. Addis Ababa: Ethiopia Federal Ministry of Health (FMoH); 2008.

34. World Health Organization. Health-Care Waste Management: Rapid Assessment Tool for Country Level. Geneva: World Health Organization (WHO); 2001

35. Vittinghoff E, Glidden DV, Shiboski SC, McCulloch CE. Regression methods in biostatistics: linear, logistic, survival, and repeated measures models. New York: Springer Science \& Business Media; 2011.

36. Sahiledengle B, Gebresilassie A, Hiko K, Getahun T. Healthcare waste segregation, treatment and disposal practice in governmental healthcare facilities in Addis Ababa, Ethiopia. Ethiop J Environ Stud Manag. 2018;11:73-85.

37. Saad SA. Management of hospitals solid waste in Khartoum state. Environ Monit Assess. 2013;185(10):8567-82.

38. Taghipour $\mathrm{H}$, Mosaferi $\mathrm{M}$. The challenge of medical waste management: a case study in Northwest Iran-Tabriz. Waste Manag Res. 2009;27(4):328-35. 
39. Abdulla F, Qdais HA, Rabi A. Site investigation on medical waste management practices in northern Jordan. Waste Manag. 2008;28(2):450-8.

40. Bassey BE, Benka-Coker MO, Aluyi HS. Characterization and management of solid medical wastes in the Federal Capital Territory, Abuja Nigeria. Afr Health Sci. 2006;6(1):59-63.

41. Gao Q, Shi Y, Mo D, Nie J, Yang M, Rozelle S, Sylvia S. Medical waste management in three areas of rural China. PLoS One. 2018;13(7):e0200889.

42. Njue PM, Cheboi KS, Oiye S. Adherence to healthcare waste management guidelines among nurses and waste handlers in Thika sub-county-Kenya. Ethiop J Health Sci. 2015;25(4):295-304.

43. Hagen DL, Al-Humaidi F, Blake MA. Infectious waste surveys in a Saudi Arabian hospital: an important quality improvement tool. Am J Infect Control. 2001;29(3):198-202.

44. Moreira AM, Günther WM. Assessment of medical waste management at a primary health-care center in São Paulo, Brazil. Waste Manag. 2013;33(1):162-7.

45. Ferreira $V$, Teixeira MR. Healthcare waste management practices and risk perceptions: findings from hospitals in the Algarve region, Portugal. Waste Manag. 2010;30(12):2657-63.

\section{Publisher's Note}

Springer Nature remains neutral with regard to jurisdictional claims in published maps and institutional affiliations.

Ready to submit your research? Choose BMC and benefit from:

- fast, convenient online submission

- thorough peer review by experienced researchers in your field

- rapid publication on acceptance

- support for research data, including large and complex data types

- gold Open Access which fosters wider collaboration and increased citations

- maximum visibility for your research: over $100 \mathrm{M}$ website views per year

At BMC, research is always in progress.

Learn more biomedcentral.com/submissions 